\title{
Fractografia de Compósitos Estruturais
}

Segurança deve ser levado a sério em todas as áreas, mas algumas delas, como é o caso da aviação, esse quesito deve atingir níveis próximos da perfeição. Aliado à segurança, outras preocupações devem existir, tais como, a econômica e ambiental e por isso quando se pensa em materiais que devem compor o sistema de sustentação de cargas aplicadas em aviões, são feitos esforços crescentes para que a leveza e alta resistência continuada garantam o crescimento sustentado adequado, com baixo consumo energético e alto nível de confiabilidade. A matéria elaborada pela Prof ${ }^{a} \mathrm{Dr}^{a} \mathrm{Mirabel} C$. Rezende do CTA, São José dos Campos, elucida com grande precisão como é possível monitorar e prever possíveis falhas em compostos poliméricos estruturais utilizados em aeronaves e porque são necessárias análises sofisticadas como a fractográfica, mesmo tendo como limite a capacitação de analistas e laboratórios.

As indústrias aeronáutica e espacial são as grandes impulsionadoras do desenvolvimento dos materiais compósitos estruturais, por necessitarem de componentes de baixa densidade e que atendam aos severos requisitos de resistência mecânica em serviço. A constante necessidade de redução de peso em aeronaves e estruturas espaciais tem continuamente impulsionado a tecnologia de processamento de compósitos estruturais. Este aumento de uso está associado à redução de peso, com maiores valores de resistências à fadiga e à corrosão, em relação ao alumínio, facilidade na obtenção de peças com geometrias complexas e flexibilidade de projeto na concepção de estruturas de forma integrada, reduzindo, assim, o número de componentes aeroembarcados.

Como muitos dos elementos estruturais utilizados no setor aeroespacial apresentam dimensões consideráveis, os materiais compósitos poliméricos representam um caso de particular relevância dentro dos materiais de engenharia não convencionais, especialmente para aplicações estruturais de uso aeronáutico.

Desde o advento das fibras de vidro, aramida e carbono, a indústria aeronáutica tem se utilizado dessa tecnologia na fabricação de peças para aeronaves. A Figura 1 ilustra o uso de materiais compósitos, em substituição aos materiais metálicos, das aeronaves Boeing 777, Airbus A-380 e do Embraer 170. Com a evolução tecnológica, os materiais poliméricos, de alta resistência estrutural, foram ganhando espaço neste segmento, podendo ser observado um crescimento desses materiais na fabricação das aeronaves, tendose hoje projetos de novas aeronaves com a previsão de uso de 50\% em peso em materiais compósitos. A Figura 2 ilustra o uso de materiais compósitos na aeronave EMB 170.

O desempenho das propriedades de um componente em uma aeronave é dependente da região em que o mesmo está atuando. Por exemplo, o aumento da resistência estática é útil principalmente em regiões de elevada intensidade de carregamento, como na asa. Em regiões de carregamento moderado, a rigidez é o principal critério de projeto, enquanto que a densidade do material é importante em qualquer parte do avião.

A indústria aeronáutica exige um controle muito rigoroso na seleção de materiais que são utilizados no projeto e na fabricação de componentes, tendo como base os dados conhecidos das diferentes cargas envolvidas durante as diversas fases de operação da aeronave. Na Figura 3 podem ser observadas as principais cargas envolvidas em uma aeronave em operação.

Como ilustração, a fuselagem de uma aeronave pode ser dividida em três secções principais: dianteira, central e traseira. As cargas predominantes durante um vôo comum são as cargas aerodinâmicas que causam flexões e torções na fuselagem; asas e empenagens. As cargas resultantes podem causar regiões de tração, compressão, flambagens e cisalhamentos. Durante o taxiamento ocorrem carregamentos dinâmicos provenientes das irregulares do solo, transferidos para a fuselagem do avião através dos trens de pouso e as cargas inerciais são as predominantes neste caso. Portanto, uma análise detalhada para a seleção dos diversos materiais e processos envolvidos no projeto e fabricação das distintas partes de um avião, adotando diferentes critérios, se faz necessária. A Figura 4 apresenta as principais propriedades

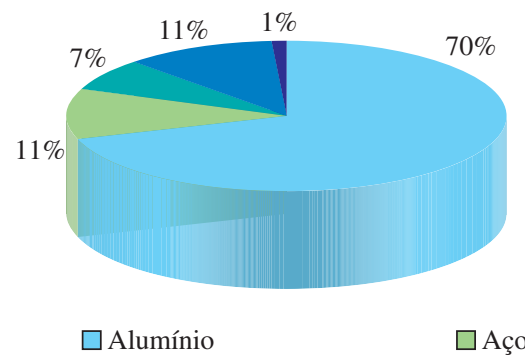

(a)

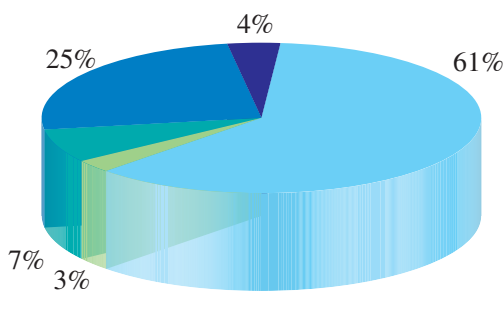

$\square$ Titânio

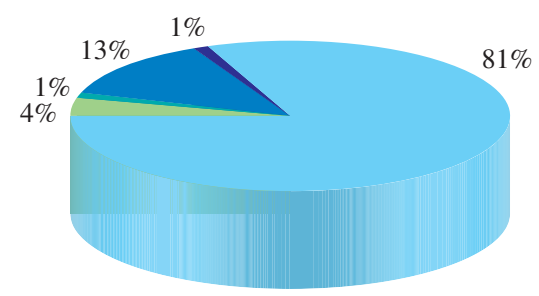

$\square$ Compósitos $\square$ Outros

(c)

Figura 1. Percentagem global dos materiais utilizados na fabricação das aeronaves (cortesia da empresa Embraer). a) distribuição \% global de peso: BOEING 777; b) distribuição \% global de peso: AIRBUS A380; e c) Distribuição \% global de peso: EMBRAER 170. 


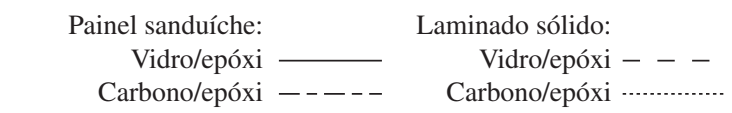

Vidro/aramida/ epóxi — - -
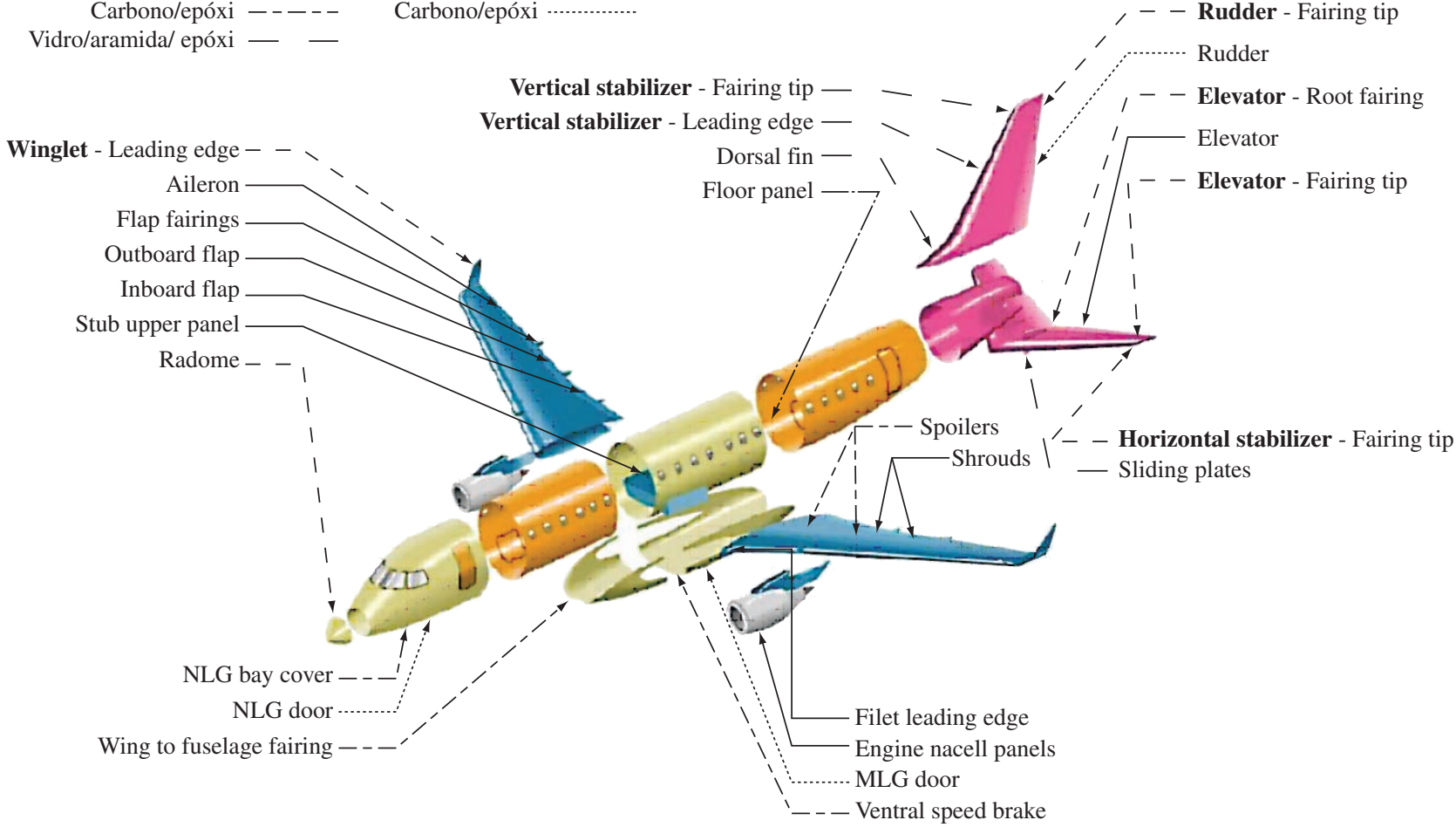

Figura 2. Vista explodida da aeronave EMB-170, mostrando os componentes fabricados em compósitos poliméricos avançados (cortesia da Embraer).

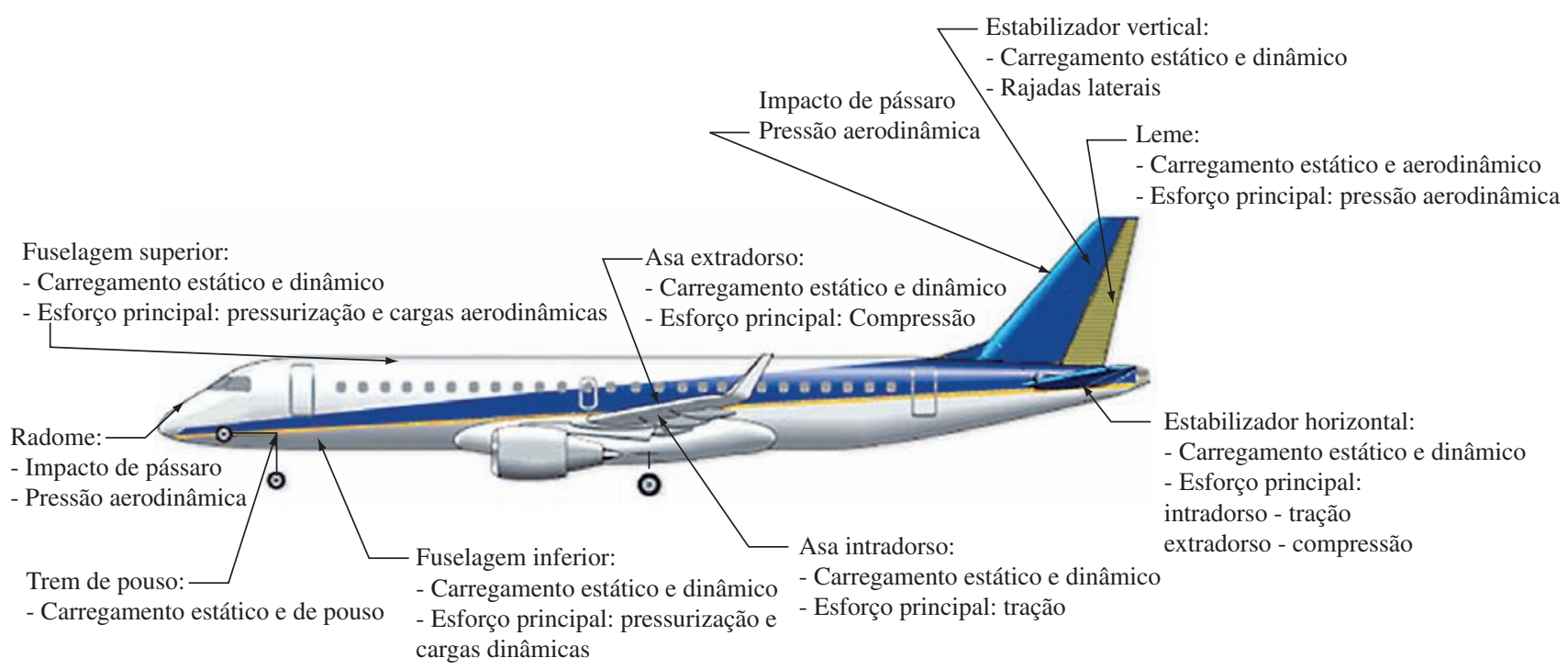

Figura 3. Principais cargas envolvidas na operação de uma aeronave (cortesia Embraer).

que devem ser adotadas durante uma análise para a seleção de materiais a serem utilizados nas fases de projeto e fabricação de uma aeronave, sendo que as principais propriedades a serem consideradas durante a fase de projeto são a resistência à tração, módulo de elasticidade, resistência à fratura e ao crescimento de trincas, resistência à corrosão sob tensão e fadiga.

Atualmente, o mercado da aviação está mais competitivo e agressivo e as companhias aéreas buscam a todo ins- tante a redução do custo operacional, com a melhoria e a redução de manutenção, associada com a alta confiabilidade operacional da aeronave.

Apesar das vantagens que os materiais compósitos apresentam e que motivam a sua utilização na indústria aeroespacial, essa classe de materiais tem como desvantagem, em comparação aos metais, a susceptibilidade aos danos, perdendo muito de sua integridade estrutural quando isso ocorre. Os danos podem ocorrer durante o processamento 


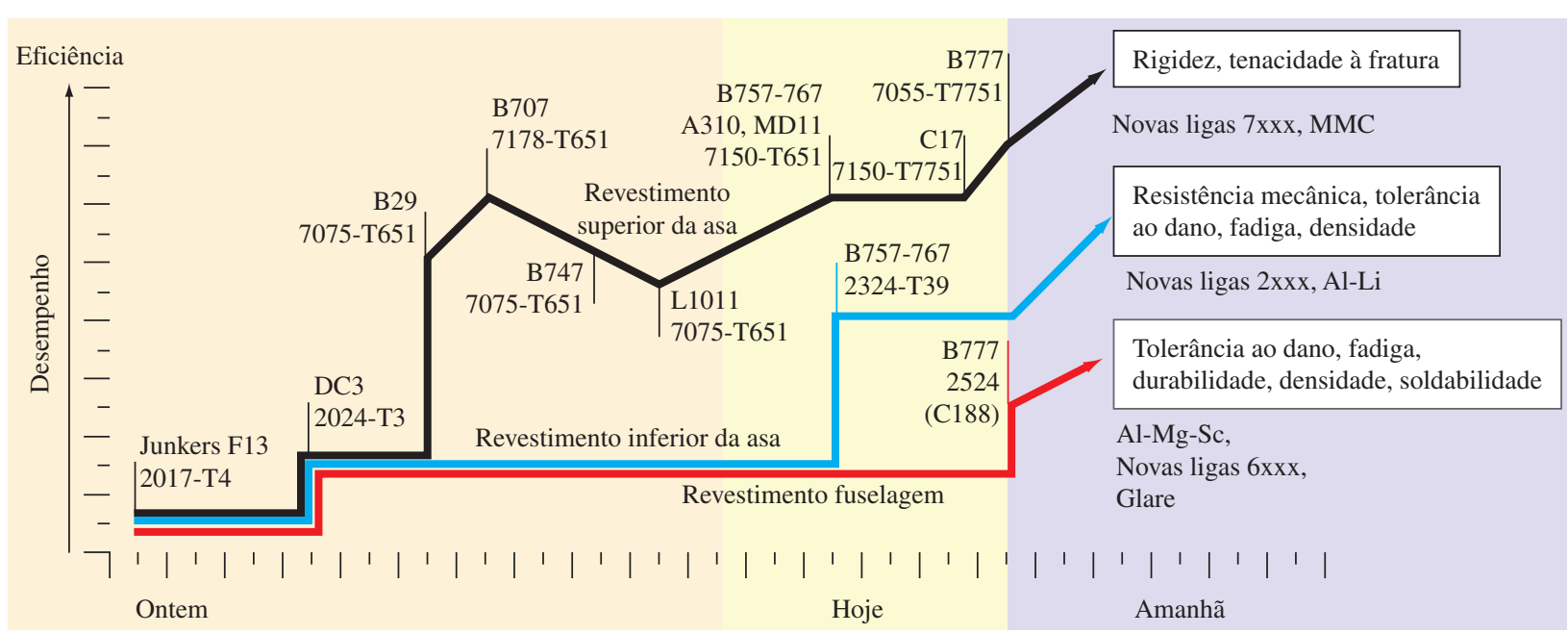

Figura 4. Evolução dos materiais utilizados nos revestimentos de aeronaves.

da matéria-prima, fabricação da peça, manuseio, transporte, armazenagem, manutenção ou em serviço.

Os danos são causados de diversas formas como descontinuidades das fibras, porosidade, delaminações, áreas pobres ou ricas em resina ou em operações que envolvam abrasão, erosão, impacto de granizo, pedras e pássaros. Os danos nem sempre são visíveis, mas podem reduzir a resistência do componente significativamente. E, quando componentes que possuem danos são expostos aos efeitos ambientais, como temperatura, umidade e/ou radiação ultravioleta, pode haver um aumento significativo da degradação de suas propriedades físicas e mecânicas.

Devido à utilização dos compósitos avançados em peças ou componentes de grande responsabilidade estrutural e de alto custo, torna-se necessária, após o estudo analítico do dano, a utilização de reparos estruturais em componentes danificados, recompondo, ao máximo, as condições estruturais de projeto da peça, deixando-a novamente em condições de uso. Essa conduta visa reduzir o custo do processamento de um novo componente (matérias-primas e mão-de-obra) para a sua substituição e de permanência da aeronave em solo, no caso da indústria aeronáutica. Assim, avaliar as variáveis e limitações envolvidas nas técnicas de reparo estrutural é de importância fundamental para assegurar que o reparo cumpra seu objetivo.

A Figura 5 exemplifica um caso real de dano em um componente aeronáutico, um estabilizador vertical, danificado em vôo pelo choque com uma ave, mostrando a gravidade do dano provocado pelo impacto. Este é um caso típico de um componente primário que necessita ser submetido ao processo de reparo estrutural. Nestes casos, o procedimento de avaliação de rotina envolve a inspeção visual da área e a inspeção por meio de técnicas não-destrutivas, por exemplo, ultra-som, que permite detectar delaminações, conforme demarcado pelas regiões hachuradas. Este dano é típico em materiais compósitos poliméricos, processados pelo uso de pré-impregnados, pelo fato da propagação do dano ocorrer preferencialmente através das camadas de préimpregnados, provocando delaminações, rompimento das fibras e microtrincas na matriz de resina. Nestes casos, a região danificada é avaliada e caso seja factível a realização do reparo, o material é removido por lixamento e o componente é reparado.

Considerando a crescente utilização dos compósitos avançados em peças ou componentes de grande responsabilidade estrutural, geralmente de elevado custo, torna-se necessário um estudo analítico detalhado de áreas danifi-

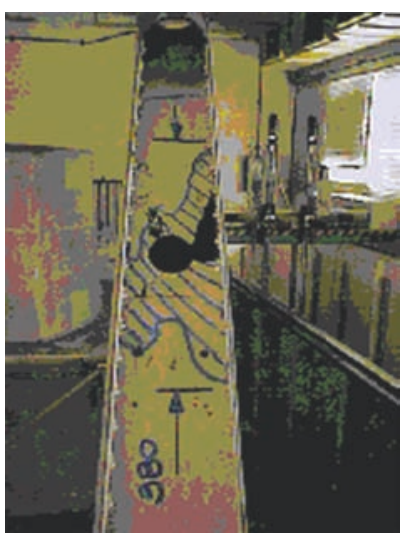

(a)

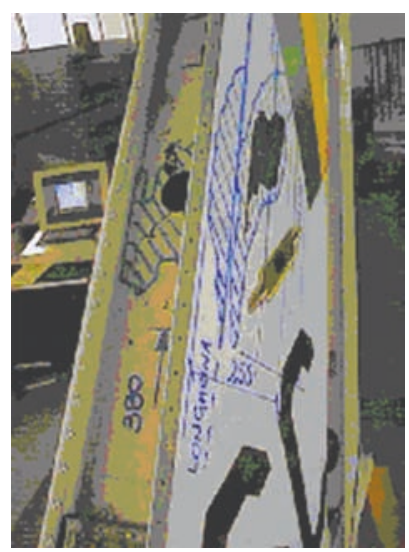

(b)

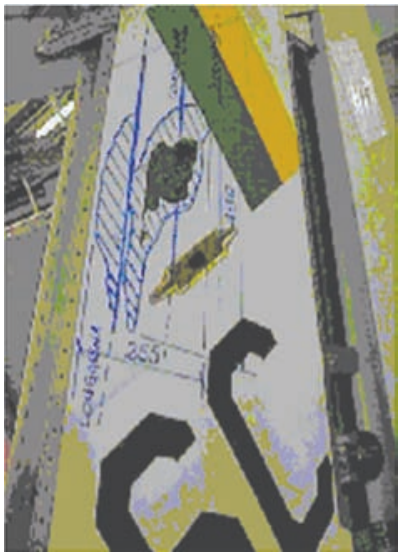

(c)

Figura 5. Estabilizador horizontal com dano. As regiões hachuradas referem-se à área a ser reparada. 
cadas ou de escombros resultantes de acidentes, de modo a avaliar as possíveis causas do dano ou do acidente, visando atender aos requisitos de segurança em vôo, verificar a possibilidade de reparo de componentes e/ou gerar orientações quanto à otimização de projetos ou de processamento de componentes.

\section{Fractografia}

A fractografia é uma das principais ferramentas utilizadas no processo de análise após danos ou falhas. Consiste em identificar aspectos fractográficos e estabelecer as relações entre a presença, ou ausência desses aspectos com a sequiência de eventos da fratura, podendo levar à determinação do carregamento e condições dos esforços no momento da falha. A fractografia confirma ou remove as suspeitas que possam recair sobre os modos de falha ocorridos. Esta área de estudos teve como um dos seus primeiros estudiosos os pesquisadores Purslow; Sohn e Hu (PURSLOW, 1986; SOHN, HU, 1995).

Esta ferramenta é a chave para se determinar a seqüência dos eventos ocorridos durante o processo de fratura e identificar o estado de tensões atuantes no momento da falha. Outros fatores como condições ambientais, defeitos do material e outras anomalias que podem contribuir para o início, crescimento e término da fratura também podem ser avaliados pelo uso da fractografia. Normalmente, esta área da pesquisa faz uso de diferentes técnicas, podendo-se citar a observação visual, óptica macroscópica, seguida da microscópica óptica, microscopia eletrônica de varredura e, em alguns casos, microscopia eletrônica de transmissão. A observação deve atentar não somente para a identificação e documentação da morfologia da falha, mas também para informações que ajudem a determinar as causas da falha. Assim, três operações básicas devem ser seguidas: (1) classificação do tipo de falha, (2) mapeamento da trinca e (3) análise química da superfície da fratura.

A primeira classificação do tipo de falha conduz a duas definições, falhas interlaminares e translaminares. Esta classificação ajuda muito, pois diferentes métodos podem ser empregados para melhor estudar cada um dos diferentes tipos de fratura. Fraturas interlaminares ou delaminações são melhores analisadas pela direção de propagação da trinca utilizando-se microscopia óptica, enquanto que as fraturas translaminares, onde ocorre o rompimento das fibras, são melhores analisadas por microscopia eletrônica de varredura.

Determinar a direção de propagação da trinca é uma tarefa das mais significativas para a fractografia. A técnica recomendada para o mapeamento da trinca usa a menor extensão possível para o cumprimento da tarefa. Isto é devido à limitação da perspectiva que se tem com o aumento da extensão, de modo que se perde a visão da fratura como um todo. Assim evita-se caracterizar a fratura, baseado apenas em informações de uma pequena área não representativa. A análise química da superfície da fratura pode ser necessária caso queira determinar a sequiência de eventos da fratura.
Com isso, pode-se determinar o ponto de origem da fratura e identificar as anomalias que deram origem ao evento.

Com uma peça fraturada em serviço, a responsabilidade inicial do investigador é documentar a superfície da fratura, tanto com fotografias quanto com fotomacrografias e fotomicrografias ópticas. Neste estágio, informações críticas importantes podem ser asseguradas localizando-se todos os tipos de fratura ocorridos, suas localizações são óbvias condições anômalas de serviço ou produção, o que dá ao investigador um sentimento de quais foram as cargas primárias no evento, qual a seqüência de acontecimentos, e que fatores poderiam ocorrer no início ou durante a falha. Após a definição do tipo de falha ocorrida, vem a parte mais trabalhosa do processo, que consiste no exame detalhado da fratura por meio de análises macro e microscópicas. Estas análises requerem que o investigador use técnicas fractográficas específicas para determinar a direção da fratura, o modo como ocorreu e as condições ambientais em que esta se processou. Para fraturas translaminares, a ênfase é dada na fratura das fibras, enquanto que na fratura interlaminar a resina recebe mais atenção.

Se a origem da fratura for identificada, o próximo passo é determinar quais condições anômalas existem na região original. Se um defeito é detectado ou suspeitado, então exames como o de análise química da superfície devem ser feitos para a determinação precisa da ocorrência.

\section{Fractografia de Compósitos Estruturais}

Os materiais compósitos poliméricos estão se tornando cada vez mais importantes em aplicações industriais, particularmente na indústria aeronáutica, onde as propriedades de alta resistência e baixa massa específica são necessárias. Como os compósitos estão sendo usados para a fabricação de peças estruturais críticas, como em estabilizadores horizontais e verticais e revestimento de asas, seu comportamento mecânico deve ser melhor entendido. Para isso, as suas propriedades devem ser muito bem caracterizadas, como ocorre com os materiais mais usuais - os metais. Assim sendo, existe um esforço muito grande para se estender os conhecimentos de resultados estabelecidos na área de análise de falhas de metais para os materiais compósitos.

Para o ramo de análise de falhas tornou-se, então, imperativo o desenvolvimento de técnicas e observações específicas para os materiais compósitos, e não somente a análise com vistas aos materiais metálicos, como ocorria em um passado recente.

Além disto, projetos de estruturas em materiais compósitos requerem um conhecimento detalhado do comportamento da fratura do material e dos modos de falha do componente, conhecimento obtido com os exames post-mortem de componentes que falharam.

$\mathrm{Na}$ análise de falhas em compósitos não é somente importante relacionar a fractografia com os mecanismos de fratura, mas também ter a habilidade de descrever cada um dos aspectos característicos sem equívocos e entender cada um dos significados, de modo a determinar de maneira pre- 
cisa o modo de fratura, a direção geral de propagação da trinca e a origem e seqüência de falhas estruturais.

É importante notar que, os diferentes tipos de falhas estão relacionados com o tipo de matriz e fibras e com a relação de adesão e interface existente entre estes elementos. As Figuras 6 e 7 apresentam vistas relativas à avaliação da interface em compósitos estruturais.

As falhas em compósitos podem ser descritas pelos mecanismos de danos que ocorrem na fratura. Esses podem ser identificados por quebra das fibras, trinca da matriz ou delaminação interlaminar. A quebra de fibras e a trinca da matriz são dependentes das propriedades de resistência dos constituintes, enquanto que a delaminação pode ser causada por anomalias durante a fabricação, seqüência de empilhamento de camadas, processo de cura ou impactos que ocorrem na vida em serviço. Com a progressão do carregamento, o acúmulo de danos ou das falhas locais existentes no laminado provocam a falha final do compósito. A falha catastrófica raramente acontece na carga correspondente à

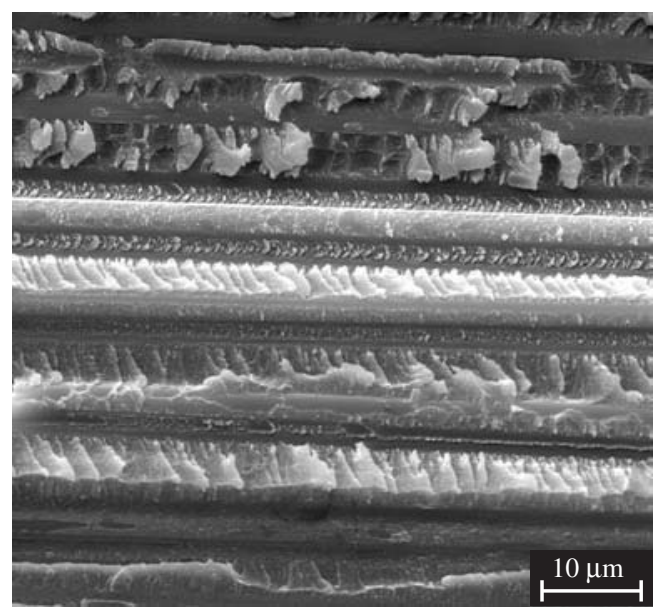

Figura 6. Interface fibra/resina no plano de falha de um laminado carbono/ epóxi seco. Na parte central da figura observa-se o efeito do arrancamento de fibra.

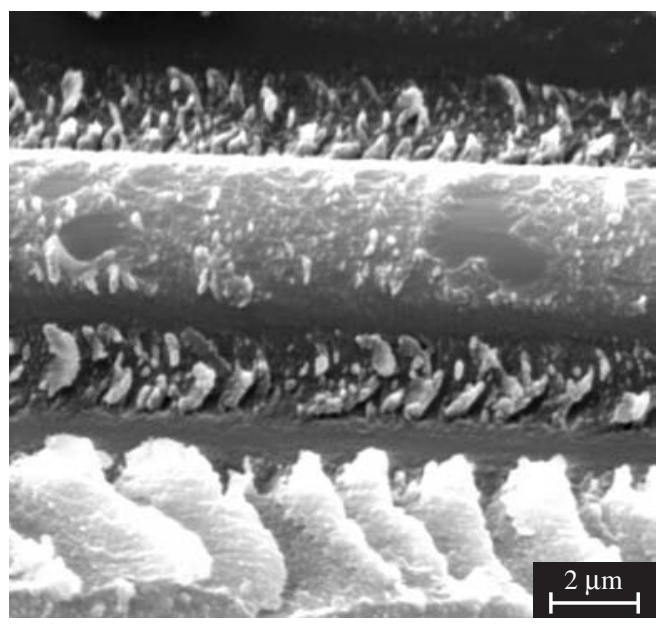

Figura 7. Vista aproximada revelando uma fibra recoberta por resina, sinalizando uma boa interface. Neste caso, a fratura do laminado não ocorreu na interface e sim na matriz. da falha inicial ou da falha da primeira camada. A falha inicial de uma camada pode ser prognosticada pela aplicação de um critério de falha apropriado ou pela teoria de falha da primeira camada. A predição da falha subseqüente requer o entendimento dos modos de falha e dos modos de propagação das falhas no laminado.

O exame da superfície fraturada ou dos componentes falhados por técnicas de microscopia permite determinar a evolução dos eventos de danos e das condições que abrangem o processo de falha. Com a revelação dos detalhes pode-se tentar reconstituir a seqüência de falhas determinando, por exemplo, o local onde se origina uma trinca e qual ou quais as causas provocaram o seu início. Desse modo, será possível obter melhor entendimento por quais modos e direções que as trincas se propagam, quais são os tipos de falhas presentes e maior facilidade para identificar as condições de carregamentos envolvidas.

Devido à construção anisotrópica dos compósitos, os danos podem ocorrer de várias maneiras. Os tipos e modos desses danos estão diretamente relacionados com a orientação das fibras e direção de aplicação do carregamento. Os modos de fratura podem ser dos tipos interlaminar, intralaminar e translaminar.

A superfície de fratura é a principal fonte de referências para se determinar a causa da falha. Nela está registrada de forma detalhada a história dos danos ou de parte dela, contendo as evidências do tipo de carregamento, os efeitos envolvidos e a qualidade do material.

A análise da origem da fratura pode revelar se a falha é causada por alguma situação especial de danos ocorridos no local, como impactos, ferramental utilizado ou outros. Quando a origem de uma fratura é determinada, destaque especial é dado à identificação da causa da falha. Diferente do que ocorre nos metais, a origem da falha nos compósitos não se limita a um pequeno ponto, dependendo do tamanho da peça, chegando a áreas de polegadas de diâmetro. Como regra geral, peças que apresentam grandes áreas de origem de fraturas ou pontos de origem, facilmente definidos como danos após falha, normalmente passaram por carregamento excessivo em toda a sua estrutura até a falha total da peça. Outra condição é a que apresenta o ponto original da falha pequeno e bem localizado, como entalhes e porosidades, de modo que a falha ocorre na maior parte das vezes abaixo da carga máxima suportada pela peça.

Cada tipo de carregamento ao qual está submetido a região fraturada gera um tipo específico de superfície de fratura. Como exemplos pode-se citar que o carregamento em tração gera efeitos como o arrancamento das fibras ( $f$ bre pull-out) (Figura 6), enquanto que o carregamento em cisalhamento interlaminar gera delaminações. Do mesmo modo, estruturas finas sobre compressão geralmente falham por flambagem ou por crescimento de delaminações ao longo das interfaces interlaminares fracas.

Também tem sido verificado que condições ambientais adversas causam uma redução significativa na resistência dos compósitos. Neste caso, o examinador deve estar atento às características de falhas ocorridas em temperaturas ou 
condições de umidade fora das especificadas para a operação da peça.

Estruturas em materiais compósitos podem falhar prematuramente devido a vários tipos de danos. Esses podem ser: trinca longitudinal ou "splitting", trinca transversal, ruptura de fibras, dano no núcleo, absorção de água, vazios, porosidades, descolamento e delaminação. Muitas vezes são originados por erros de projeto, ou durante o processo de fabricação ou na utilização em serviço.

Dependendo do arranjo interno, os compósitos apresentam diferentes propriedades físicas. Isto implica no projeto de uma perfeita seqüência de empilhamento de camadas e orientação das fibras, uma vez que um simples desvio de $5^{\circ}$ na orientação dos reforços pode reduzir drasticamente, em até $54 \%$, a resistência do produto final.

Outros efeitos da manipulação inadequada deste tipo de material podem ser observados no campo das tensões internas, sendo um facilitador do surgimento e propagação de trincas e falhas de peças. Uma sequiência errada no empilhamento das camadas pode se tornar um problema quando ocorrer uma expansão térmica, uma vez que as propriedades das camadas são anisotrópicas, gerando tensões residuais internas durante o processo de fabricação ou operação da peça.

Para os compósitos de fibras contínuas, as propriedades que precisam ser conferidas para determinar se não ocorreram discrepâncias são: módulo de Young, resistência básica dos laminados, sensibilidade a entalhes, estabilidade em flexão; condições de tensão interna térmica ou residual e alterações devido à sensibilidade a mudanças ambientais. Os erros mais comuns cometidos no projeto ou processamento dos compósitos durante o processo de empilhamento são: falta ou adição de camadas; orientação angular imprópria; e o tipo da trama das fibras da camada.

Erros no empilhamento das camadas e orientação das fibras, na formulação química da matriz polimérica e na cura da resina também contribuir para que ocorra uma falha prematura da peça. Os principais fatores contribuintes para falhas prematuras são: especificação incorreta dos materiais, empilhamento incorreto do material, isto é, número, orientação e seqüência de empilhamento; conteúdo de fibra e matriz, porcentagem de vazios inadequada, espessura da camada individual e alinhamento impróprio das fibras, composição da resina imprópria; grau de cura da resina incompleto, contaminantes, elevada retenção de umidade; posicionamento, tamanho e pouca qualidade dos detalhes, furos etc; e instalação de rebites, adesivos mal especificados.

Qualquer variação nas condições de serviço que afete significativamente a resposta mecânica do laminado ou as propriedades químicas dos componentes do compósito pode conduzir a uma falha prematura. As principais variações que induzem a falhas nos compósitos são: temperatura, composição química do ambiente, e situações de cargas extremas.

A Figura 7 mostra a proximidade da interface fibra/resina de um laminado carbono/epóxi seco à temperatura ambiente, onde se observa uma boa ancoragem da resina nas fibras. Neste caso, o compósito tem uma região de ancoragem da matriz na fibra mais bem definida, característica essencial para se obter os melhores resultados de resistência ao cisalhamento interlaminar no ensaio mecânico. É através dessa interação fibra/resina que as tensões são transferidas da resina para a fibra, quando o laminado é solicitado pelo carregamento em flexão. A análise cuidadosa dessa região (Figura 7) revela que as fibras estão recobertas por uma fina camada de resina, sugerindo que o cisalhamento ocorreu na região da matriz polimérica preferencialmente, ao contrário de uma falha que ocorre na interface fibra/resina, evidenciada pelo fato do reforço mostrar-se liso e sem resíduos da matriz polimérica.

O domínio da fractografia de compósitos permite identificar os diferentes esforços que atuaram em um componente. Esta identificação dá condições e ferramentas para se determinar a causa do dano e definir medidas corretivas e preventivas no processamento, manutenção e reparo de compósitos.

A Figura 8 ilustra uma fratura com duas regiões de transição. A primeira transição se dá entre a área de tração (a) e a de flexão (b). Esta zona de transição é observada pelo topo das fibras, onde se pode visualizar uma região de tração e outra de flexão. A partir de um ponto crítico, onde a flexão se torna mais severa, a transição é feita por uma fenda, uma trinca muito profunda, e a parte em tração é separada da

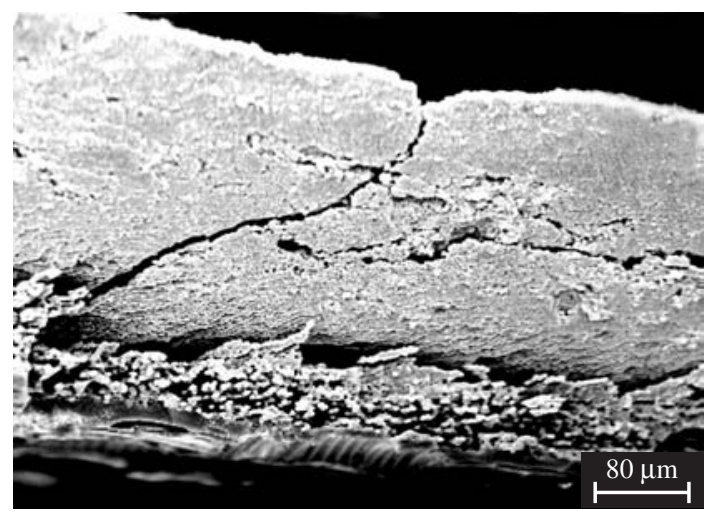

(a)

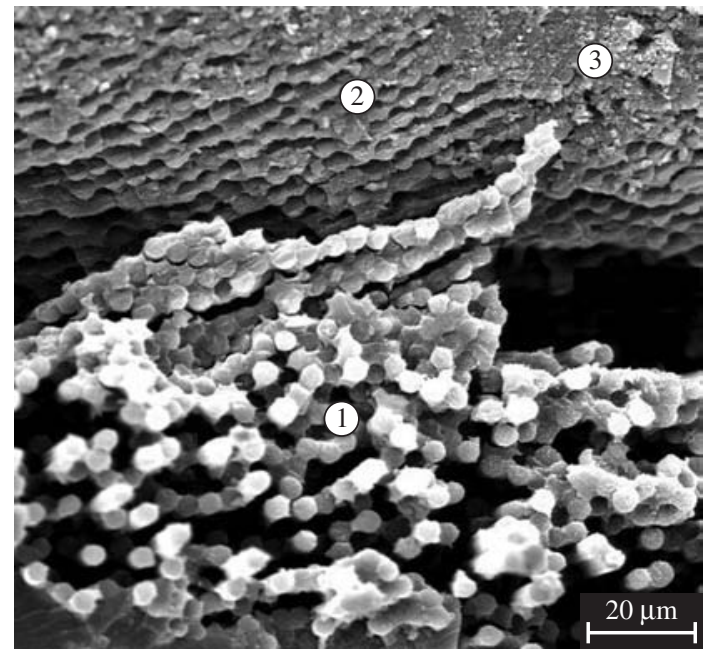

(b)

Figura 8. a) Vista geral de uma superfície de fratura; e b) detalhe das zonas de transição entre tração (1), flexão (2) e compressão (3). 
parte em flexão pura. A segunda transição ocorre de maneira mais sutil, entre a zona de flexão (b) e a de compressão (c), que recobre toda a superfície da amostra, exceto das bordas, onde se encontram os efeitos da tração e flexão.

A sofisticação da análise fractográfica tem como limite a capacitação do analista e dos recursos laboratoriais. Como exemplo tem-se a identificação de um dos mais importantes aspectos fractográficos dos compósitos, que são os padrões de linhas radiais freqüentemente encontrados em superfícies de fratura por tração em fibras de carbono. A observação deste aspecto, chamado linhas radiais, possibilita determinar a origem da falha e a direção de propagação da trinca pela fibra, que leva à formulação do conceito de Falha de Fibra Diretamente Atribuível (DAFF). Usando a DAFF é possível se traçar o caminho de fratura por áreas significantes da falha e, com um número significativo de áreas, se determinar a direção geral da fratura por tração no componente de compósito.

Esta região cuja superfície apresenta aspectos clássicos de tração fornece preciosas informações sobre como se originaram e propagaram as trincas. Nesta região de fratura sob tração é possível se aplicar a DAFF, de modo a se determinar a direção de propagação das trincas e, assim, se determinar por onde a falha se propagou. Como pode ser observada, a falha se propaga das bordas para o interior da amostra, no sentido da região de tração para a região de flexão. A Figura 8(a) mostra que a falha por tração ocorre somente em um lado da amostra, sendo este o local de origem da fratura.

Um fator que ocorre na parte em tração pura é o arrancamento das fibras, o efeito pull-out. Esta evidência é ilustrada na Figura 9, nos locais indicados pelas setas. Um fator a ser observado é a presença de resina aderida às laterais das fibras, indício de uma boa interface reforço-matriz.

Na Figura 10, as setas mostram a aplicação da DAFF, indicando a direção em que a trinca se propaga nas fibras. Percebe-se o aspecto raiado no topo das fibras, com clareza no ponto de origem da falha na fibra.

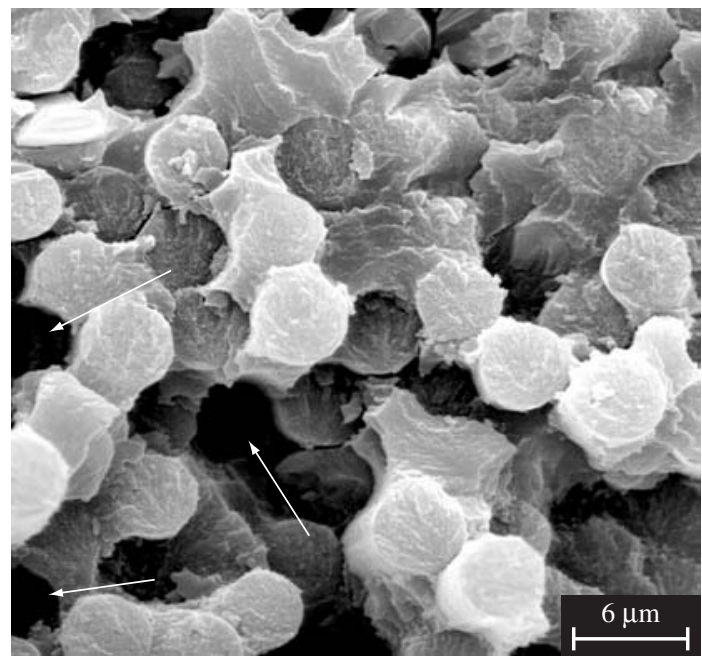

Figura 9. Vista da superfície da fratura, com locais com arrancamento de fibras. Observa-se resina aderida às laterais das fibras, indicando uma boa interface.
Ao se caminhar mais para o interior da amostra observase a região de transição entre tração pura e flexão pura. Esta transição tem início na tração das fibras e passa por uma região onde as fibras apresentam aspectos de tração e flexão simultaneamente, verificados em seus topos. Esta transição tração - tração/flexão está retratada na Figura 11.

A análise detalhada da região de tração/flexão mostra aspectos indicativos do caminho percorrido pela trinca nos topos das fibras. A Figura 12 indica por setas as linhas de propagação da falha, bem como o aspecto de tração/flexão no topo das fibras.

A partir deste ponto, ao se caminhar para o interior do laminado, as fibras passam a apresentar apenas o aspecto de flexão. Isto é evidenciado pela diferença de inclinação e de rugosidade no topo das fibras, as vezes até com diferença de cavidade e concavidade no topo das fibras.

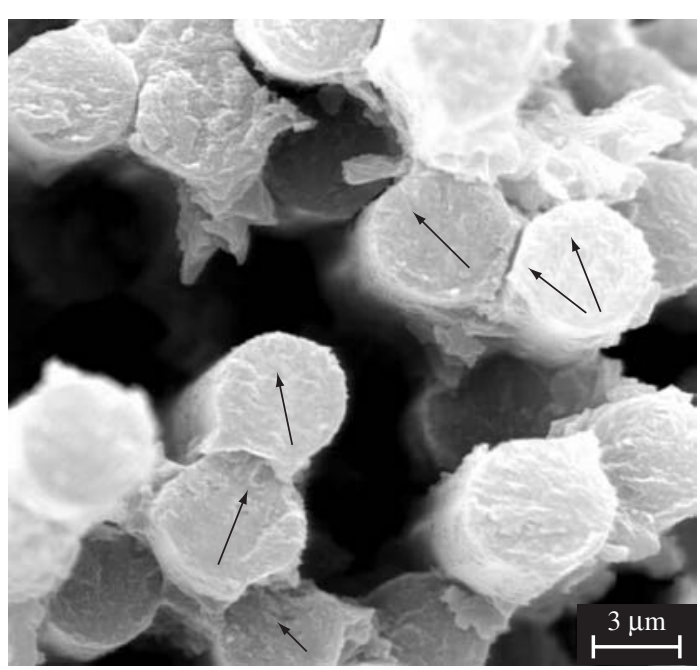

Figura 10. Indicação da direção de propagação da falha pelas fibras.

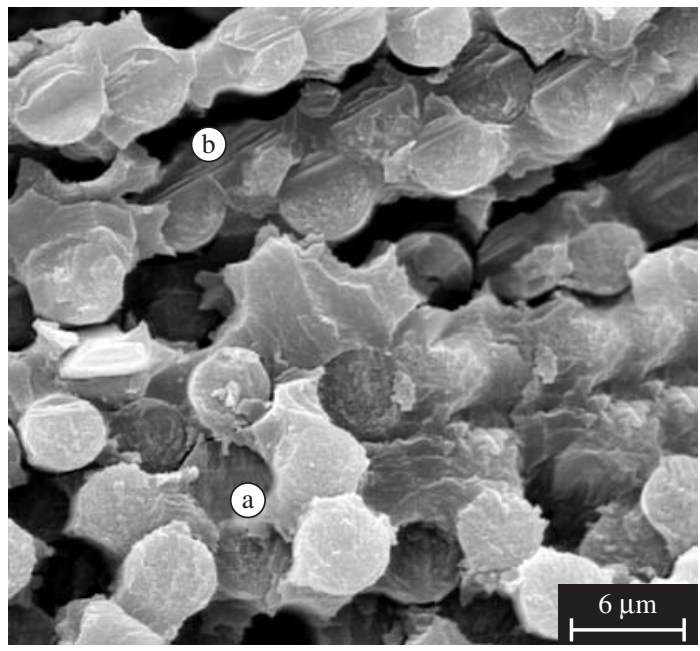

Figura 11. Local de início da transição da região de tração (a) para a b) região de tração/flexão (b). 


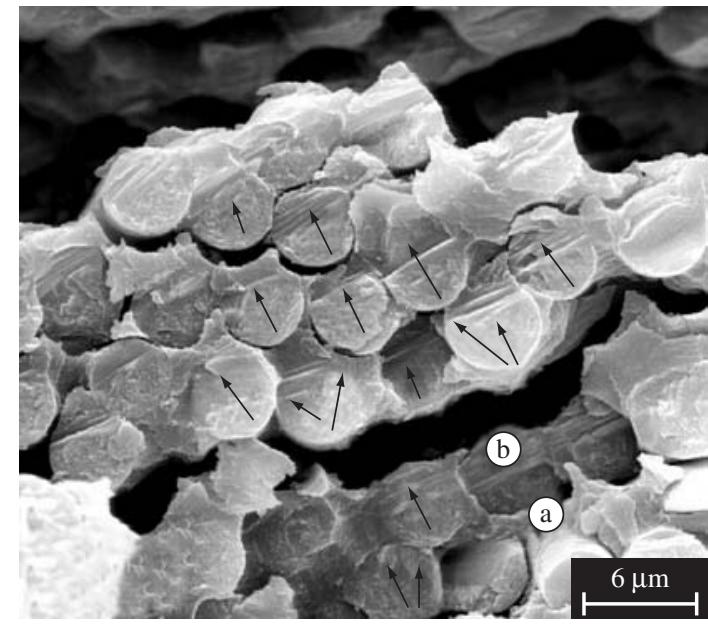

Figura 12. Vista da região com fibras em transição de tração (a) para flexão (b). As setas indicam a direção de propagação da trinca.

\section{Considerações Finais}

Apesar da importância deste assunto, existe uma quantidade resumida de trabalhos na área de danos em compósitos, tratando sobre os mais diversos assuntos, onde diferentes abordagens são utilizadas por seus autores. Observa-se também, através de pesquisas, que poucos trabalhos estão disponibilizados na área de investigação de danos em compósitos aeronáuticos e espaciais, principalmente no Brasil. Talvez esta constatação seja um reflexo da restrição desta área, disponibilizando os estudos e os resultados aos órgãos governamentais ligados ao setor de pesquisa e emissão de laudos de acidentes do setor aeroespacial.

No entanto, estudos de fractografia de compósitos estruturais vêm lançando nova luz sobre muitos aspectos fundamentais e contribuindo para um maior entendimento da origem dos aspectos encontrados nas superfícies de fratura de compósitos poliméricos de fibra contínua. Estes trabalhos têm contribuído para a elucidação da causa da falha final em estruturas de materiais compósitos e criando uma capacitação nacional na análise de superfícies de fratura e danos.

\section{Agradecimentos}

Agradeço a parceria nos trabalhos envolvendo fractografia de compósitos e também enalteço a competência dos pesquisadores Edson Cocchieri Botelho da FEG/UNESPGuaratinguetá; Geraldo Maurício Cândido e Leandro Augusto Lemos Franco da Divisão de Materiais/IAE/CTA; Rogério de Almeida Silva e Sergio Mayer da Embraer.

\section{Referências utilizadas}

1. Franco, L. A. L. - "Análise fractográfica de compósitos poliméricos estruturais", Dissertação de Mestrado, Instituto Tecnológico de Aeronáutica (2003).

2. Purslow, D. - Composites, 12, 4, p.241-247 (1981).

3. Purslow, D. - Composites, 15, 1, p.43-48 (1984).

4. Purslow, D. - Composites, 15, 2, p.112-120 (1984).

5. Purslow, D. - Composites, 17, 4, p.289-303 (1986).

6. Purslow, D. - Composites, 18, 5, p.365-374 (1987).

7. Purslow, D. - Composites, 19, 2, p.115-126 (1988).

8. Purslow, D. - Composites, 19, 5, p.358-366 (1988).

9. Purslow, D. - J. Materials Science, 8, 5, p.617-617 (1989).

10. Silva, R. A. - "Processamento de compósitos metal/fibraestudo de interface", Tese de Doutorado, Instituto Tecnológico de Aeronáutica 2003.

11. Mayer, S. - "Influência do condicionamento ambiental na resistência à tração de laminados de compósitos poliméricos reparados", Dissertação de Mestrado, Instituto Tecnológico de Aeronáutica (2003).

12. Sohn, M.-S. \& Hu, X.-Z. - Composites, 26, 12, p.849-858 (1995).

Matéria elaborada pela $\operatorname{Prof}^{a} \mathrm{Dr}^{a}$ Mirabel C. Rezende, Divisão de Materiais/IAE/CTA, São José dos Campos/SP 